\title{
Efficient sequential screening with informational externalities
}

\section{Boaz Zik ${ }^{1}$}

Received: 15 December 2020 / Accepted: 19 January 2022 / Published online: 12 February 2022

(c) The Author(s) 2022

\begin{abstract}
A seller of an item faces a potential buyer whose valuation of the item depends on two private signals. It is well known that when there are informational externalities and the buyer's private signals arrive all at once, it is impossible to implement an efficient sale. I show that if the buyer's private signals arrive over time, then the seller can implement an efficient sale even in the presence of informational externalities. Specifically, I present a novel condition on the relationship between the buyer's valuation and the social welfare that is necessary and sufficient for efficient sequential implementation.
\end{abstract}

Keywords Efficient mechanisms - Sequential screening · Efficient privatization · Interdependent valuations $\cdot$ Multidimensional information $\cdot$ Informational externalities

JEL Classification D42 · D44 · D62 · D82

\section{Introduction}

When a government is considering selling an item to a potential buyer, whether it is a permit, a license, or a physical asset, it often wants to implement an efficient allocation. That is, it wants to sell the item to the buyer if and only if the social welfare in the case where the buyer receives the item is greater than the social welfare in the case where the government keeps the item. Many times the buyer receives private information that affects social welfare and hence the efficient allocation. It is

\footnotetext{
I am grateful to an anonymous associate editor and two anonymous referees for their helpful feedback and valuable comments. I also thank Alex Gershkov, Daniel Krähmer, Ilan Kremer, Benny Moldovanu, Motty Perry, Phil Reny, Assaf Romm, and participants of various seminars for their suggestions. Funding by the German Research Foundation (DFG) through CRC TR 224 (Project B01) is gratefully acknowledged.
}

Boaz Zik

bzik@uni-bonn.de

1 Institute for Microeconomics, University of Bonn, Bonn, Germany 
often the case where the buyer's information is multidimensional and where there are informational externalities, i.e., situations where the buyer receives private information about multiple parameters that affect social welfare not only by affecting the buyer's valuation but also by affecting other aspects of social welfare. The externalities may be pecuniary. For example, consider a firm asking for a production right license in an oligopolistic market that has private information about its marginal cost and about its fixed cost. The firm's information about its costs affects the equilibrium price which in turn affects not only the firm's profits but also the profits of other firms and the consumer surplus. The externalities may be real. For example, an energy factory that applies for a drilling permit and holds private information about the amount of waste and air pollution it will produce. This information affects not only the firm's profit but also the quality of the environment. Externalities also arise in the presence of interdependent valuations, i.e., in environments where the buyer's private information also affects the payoff of the government if it decides to keep the item. Unfortunately, Maskin (1992), Dasgupta and Maskin (2000), and Jehiel and Moldovanu (2001) have shown that in environments with multidimensional information and informational externalities it is (generically) impossible to implement an efficient sale. ${ }^{1}$

In this paper, I show that this impossibility result corresponds to the case where the buyer knows all of her private information before the selling mechanism is activated. I show that if the buyer's private information arrives over time and if the selling mechanism can be activated before the buyer is exposed to all of her private information, then an efficient sale can be implemented even in the presence of informational externalities. Specifically, I present a novel condition on the relationship between the buyer's valuation and the social welfare that is necessary and sufficient for efficient sequential implementation. This condition is satisfied in natural environments with informational externalities.

I consider the following model. There is a seller of an item facing a potential buyer. The buyer receives two payoff-relevant signals sequentially. The signals are positively correlated; i.e., the realizations of each signal are ordered by the conditional distributions they impose on the other signal via first-order stochastic dominance. ${ }^{2}$ I first consider static environments, where the selling mechanism is activated after the buyer knows the realizations of both signals. In a static environment, a (deterministic) mechanism is implementable if and only if it sets a single price for the item, see, e.g., Myerson (1981). In the paper's model, where the buyer's valuation is a two-dimensional function, this condition translates to the following condition: a (deterministic) decision rule is implementable if and only if it is monotonic with respect to the buyer's signals and its boundary coincides with one of the buyer's valuation isovalue curves, see Maskin

\footnotetext{
${ }^{1}$ Maskin (1992) and Dasgupta and Maskin (2000) show impossibility results in the case of the allocation of an indivisible good. Jehiel and Moldovanu (2001) show a more general impossibility result that includes the setting of the allocation of an indivisible good as a special case.

2 This formulation of the sequential screening model is different from the standard formulation of the sequential screening model that appears in Courty and Li (2000). Courty and Li's (2000) formulation does not explicitly account for the payoff effect of the buyer's signals and the correlation between them. Rather, it only accounts for how the buyer's information in the first period affects her conditional distribution over her realized values in the second period. In the Related Literature subsection, I discuss why using the paper's formulation is required to analyze efficient allocation and why Courty and Li's (2000) formulation is adequate for the study of profit maximization.
} 
(1992), Dasgupta and Maskin (2000), and Jehiel and Moldovanu (2001). I then consider sequential environments, where the selling mechanism is activated before the buyer learns the realization of the second signal. In a sequential environment, a (deterministic) mechanism is implementable if and only if it assigns higher types in the first period, i.e, types who face higher probabilities of receiving higher valuations, lower prices for the item in the second period, see Krähmer and Strausz (2011). I show that in the paper's formulation of the sequential screening model, this condition translates to the following condition: a (deterministic) decision rule is implementable by a sequential mechanism if and only if it is monotonic with respect to each of the buyer's signals and its boundary is steeper than the buyer's valuation isovalue curves.

I use these results to compare the possibility of efficient implementation between static and sequential environments. For this purpose, I examine the effect of the buyer's information on the social welfare. In situations where the effect of the buyer's information on the social welfare is limited to its effect on the buyer's value, efficiency is implementable in both static and sequential environments. This is because the boundary of the efficient decision rule coincides with one of the buyer's isovalue curves. By contrast, in situations where the buyer's information has other externalities on the social welfare, efficient implementation is typically impossible in static environments. This is because the boundary of the efficient decision rule does not coincide with any of the buyer's isovalue curves. Nonetheless, efficient implementation may be possible in sequential environments because the boundary of the efficient decision rule can be steeper than the buyer's isovalue curves even in the presence of informational externalities. Specifically, I show that efficiency is implementable in a sequential environment if and only if the ratio between the effects of the first and the second signals is greater with respect to the social welfare than with respect to the buyer's valuation.

I then consider the case where the above condition does not hold, i.e., in which the boundary of the efficient decision rule is flatter than the buyer's isovalue curves. In this case, if the seller can reverse the order in which the buyer's signals arrive, then the boundary of the efficient decision rule is steeper than the buyer's isovalue curves and the seller can implement an efficient sale. On the other hand, when the seller cannot reverse the order of the signals, I show that the second-best sequential mechanism implements a decision rule that is implementable by a static mechanism, i.e., the seller's second-best payoff is the same in both static and sequential environments. That is, in a sequential environment, when the buyer's signals do not arrive at the right order, then not only that full efficiency cannot be attained but the sequential arrival of the buyer's signals does not even improve the second-best outcome with respect to the static case.

Finally, I present several applications in which the buyer's private information has externalities on the social welfare. The results of the paper imply that in these environments efficiency cannot be implemented by a static mechanism but can be implemented by a sequential mechanism. The applications include the efficient sale of a government's asset to a monopoly, the optimal choice of a project by a firm's CEO, and the efficient allocation of an item to buyers who have interdependent valuations.

This paper focuses on environments with a single buyer. Nonetheless, it is straightforward to extend the analysis to the case of multiple buyers. I discuss how the analysis in the paper can be carried through to the case of multiple buyers but I do not provide 
a formal analysis for the sake of not overextending the paper. The rest of the paper is organized as follows. In the rest of this section, I present an application of efficient privatization and discuss the related literature. In Sect. 2, I present the model. In Sect. 3, I compare static implementation with sequential implementation. In Sect. 4, I discuss efficient implementation and present several applications of the results of the paper. Section 5 is devoted to a discussion. The "Appendix" includes extensions and proofs.

\section{Efficient privatization}

As an illustration of the results of the paper, consider the following application. A government that owns a plant is considering whether to use it independently or to sell it to a private firm that would then hold a monopoly in the market. The government wants to implement an efficient sale, that is, to sell the plant if and only if the value of the social welfare in case of a sale is greater than its value in the case of no sale. The social welfare in the case of no sale would be some constant known to the government. The social welfare in the case of a sale would be the sum of the firm's profit and the consumer surplus. The firm can conduct two tests, one to reveal its marginal cost and the other to reveal its fixed cost. The government for its part can decide which tests will be conducted and in what order. The demand is commonly known and so both the firm's profit and the consumer surplus can be deduced from any result of the tests. The results of the paper show that if the government employs the selling mechanism after the firm has conducted both tests, then an efficient sale cannot be implemented. However, the government can implement an efficient sale if it uses the following sequential mechanism. First, the firm conducts the test that reveals its marginal cost. Then the firm receives a menu of options, and each option provides the firm with the right to buy the plant at a specified price. Lastly, the firm conducts the test that reveals its fixed cost and decides whether to buy the plant at the specified price. ${ }^{3}$

The explanation for this outcome is the following. The firm's information about its marginal cost affects the social welfare both through its effect on the firm's profit and through its effect on the consumer surplus. The firm's information about its fixed cost affects the social welfare only through its effect on the firm's profit. Therefore, the boundary of the efficient decision rule is strictly steeper than the firm's profit isovalue curves. This implies that the efficient decision rule is not implementable by a static mechanism but is implementable by a sequential mechanism.

\footnotetext{
3 The problem of efficient privatization in a static setting in which firms have private information about their marginal and/or fixed costs has been considered in several papers. Dana and Spier (1994) consider the case where the firms have private information either about their marginal cost or about their fixed cost but not both, in such a case efficient privatization is possible; Jehiel and Moldovanu (2004) consider the case where the firms have private information about both their marginal costs and their fixed costs and show that efficient privatization is impossible.
} 


\section{Related literature}

This work connects the literature on sequential screening see, e.g., Courty and Li (2000), Esô and Szentes (2007a, b), and Krähmer and Strausz (2011, 2015a, b, 2017), ${ }^{4}$ to the literature on the impossibility of efficient implementation in environments with multidimensional information and informational externalities, see, Maskin (1992), Dasgupta and Maskin (2000), and Jehiel and Moldovanu (2001). The existing sequential screening literature focuses on profit maximization. The sequential screening model is introduced in Courty and $\mathrm{Li}$ (2000) who derive a revenue equivalence result and provide regularity conditions that guarantee the implementability of the optimal decision rule. The revenue that the seller can achieve depends on the distribution of the first-period signal and its effect on the distribution of the buyer's final valuation. This property enables (Courty and $\mathrm{Li} 2000$ ) to analyze profit maximization by using a formulation of the sequential screening model that considers how the first-period signal affects the conditional distribution of the final valuation. Specifically, their formulation does not describe how the conditional distribution depends on the first-period signal's payoff effect, i.e., its effect on the buyer's valuation function, its correlation with the second-period signal, and the payoff effect of the second-period signal. To analyze efficient implementation, I use a formulation of the sequential screening model that considers the payoff effect of both of the buyer's signals and the correlation between them. I find that the implementation of efficiency is determined by the relationship between the variation of the buyer's valuation and the variation of the social welfare with respect to both of the buyer's signals. That is, it depends on the payoff effect of both of the buyer's signals and on the order in which they arrive and it is independent of the correlation between the buyer's signals.

This paper also relates to other works that present positive results on efficient implementation in environments with multidimensional information and informational externalities. Mezzeti (2004) shows that in settings where it is possible to condition transfers on realizations of payoffs, efficiency can be implemented in static environments. The paper's results show that in sequential environments it is possible to implement efficiency even in settings that require both the allocation and transfers to depend only on agents' signals. Johnson et al. (2007) show that in static environments if the agents' signals are correlated and satisfy a stochastic relevance condition then efficient Bayesian implementation is (approximately) possible. The paper's results show that in sequential environments it is possible to implement efficiency even when the buyer's information is independent of any other source of information that may be available for the seller. In dynamic settings, Liu (2017) uses correlation among types and $\mathrm{He}$ and $\mathrm{Li} \mathrm{(2016)} \mathrm{use} \mathrm{transfers} \mathrm{that} \mathrm{are} \mathrm{contingent} \mathrm{on} \mathrm{payoff} \mathrm{realizations,} \mathrm{to} \mathrm{induce}$ efficiency.

\footnotetext{
4 More works on sequential screening include Baron and Besanko (1984), Dai et al. (2006), Hoffmann and Inderst (2011), Nocke et al. (2011), Bergemann and Wambach (2015), Deb and Said (2015), Li and Shi (2017). More general models of dynamic mechanism design include Battaglini (2005), and Pavan et al. (2014). For works on efficient dynamic mechanism design in environments with private values see Bergemann and Valimaki (2010) and Athey and Segal (2013).
} 


\section{The model}

Consider a seller (he) of a single item facing a potential buyer (she). There are two periods, 1 and 2 . The buyer receives a private signal $\theta^{1} \in[0,1]$ in period 1 , and a private signal $\theta^{2} \in[0,1]$ in period 2 . These signals are distributed by a probability distribution $F\left(\theta^{1}, \theta^{2}\right)$, and $F$ is commonly known. I assume that for every $j, i \in\{1,2\}$ with $j \neq i, F\left(\theta^{j} \mid \theta^{i}\right)$ is strictly decreasing in $\theta^{i}$; i.e., $\left\{F\left(\theta^{j} \mid \theta^{i}\right)\right\}_{\theta^{i} \in[0,1]}$ are ordered by first-order stochastic dominance. The buyer's valuation $V$ is a function of her signals $V:[0,1]^{2} \rightarrow \mathbb{R}_{+}$. I assume that $V$ is continuously differentiable and strictly increasing in $\theta^{1}$ and $\theta^{2}$. I also consider the case where $V$ is independent of $\theta^{1}$, and the case where $\theta^{1}$ and $\theta^{2}$ are statistically independent. The buyer's payoff is her value of the item, in case she gets the item, minus her payment to the seller. I denote by $A$ the set of feasible allocations $A=\{0,1\}$, where 1 is the allocation that assigns the item to the buyer, and 0 is the allocation that assigns the item to the seller. A decision rule is a function ${ }^{5} q: \Theta \rightarrow A$. A social choice function, $s$, assigns an allocation and a payment to the seller for every realization of signals, i.e., $s(\theta)=(q(\theta), t(\theta))$, where $q(\theta) \in A$ and $t(\theta) \in \mathbb{R}$.

\section{Implementation}

In this section, I present characterizations of the sets of implementable decision rules in static and sequential environments and compare them. I start with an analysis of static mechanisms that are activated after the buyer has been exposed to both her signals $\theta^{1}$ and $\theta^{2}$. By the revelation principle (e.g., Myerson 1981) I restrict attention to direct mechanisms. I say that a social choice function $(q(\theta), t(\theta))$ is implementable by $a$ static mechanism if for every $\left(\theta^{1}, \theta^{2}\right)$ we have

$$
\left(\theta^{1}, \theta^{2}\right) \in \underset{\left(\hat{\theta}^{1}, \hat{\theta}^{2}\right) \in[0,1]^{2}}{\arg \max } V\left(\theta^{1}, \theta^{2}\right) \cdot q\left(\hat{\theta}^{1}, \hat{\theta}^{2}\right)-t\left(\hat{\theta}^{1}, \hat{\theta}^{2}\right)
$$

I say that a decision rule $q(\theta)$ is implementable by a static mechanism if there exists a transfer function $t(\theta)$ such that $(q(\theta), t(\theta))$ is implementable by a static mechanism. The following claim follows from standard arguments of static implementation analysis.

Claim 1 A decision rule $q(\theta)$ is implementable by a static mechanism if and only if it is of the following form:

$$
q(\theta)= \begin{cases}1 \text { if } & V\left(\theta^{1}, \theta^{2}\right)>C \\ 0 \text { or } 1 \text { if } & V\left(\theta^{1}, \theta^{2}\right)=C \\ 0 & \text { otherwise }\end{cases}
$$

\footnotetext{
5 I consider deterministic mechanisms because I focus on efficiency, and efficient decision rules are deterministic. In "Appendix B", I discuss the implications of my focus on deterministic mechanisms.
} 
for some $C \in \mathbb{R}$.

I proceed to analyze sequential mechanisms. A sequential mechanism maps a pair of the buyer's actions, one in each period, to an allocation and a transfer. By the revelation principle for sequential games (e.g., Myerson 1986) I restrict attention to direct mechanisms. I say that a social choice function $(q(\theta), t(\theta))$ is implementable by a sequential mechanism if the following conditions hold:

(i)

$$
\begin{aligned}
& E_{\theta^{2}}\left[V\left(\theta^{1}, \theta^{2}\right) \cdot q\left(\theta^{1}, \theta^{2}\right)-t\left(\theta^{1}, \theta^{2}\right) \mid \theta^{1}\right] \\
& \geq E_{\theta^{2}}\left[V\left(\theta^{1}, \theta^{2}\right) \cdot q\left(\hat{\theta}^{1}, \hat{\theta}^{2}\left(\theta^{2}\right)\right)-t\left(\hat{\theta}^{1}, \hat{\theta}^{2}\left(\theta^{2}\right)\right) \mid \theta^{1}\right]
\end{aligned}
$$

for every $\theta^{1} \in[0,1]$ and $\hat{\theta}^{1} \in[0,1]$ and every $\hat{\theta}^{2}:[0,1] \rightarrow[0,1]$.

(ii)

$$
\begin{aligned}
& V\left(\theta^{1}, \theta^{2}\right) \cdot q\left(\theta^{1}, \theta^{2}\right)-t\left(\theta^{1}, \theta^{2}\right) \\
& \geq V\left(\theta^{1}, \theta^{2}\right) \cdot q\left(\theta^{1}, \hat{\theta}^{2}\right)-t\left(\theta^{1}, \hat{\theta}^{2}\right)
\end{aligned}
$$

for every $\left(\theta^{1}, \theta^{2}\right) \in[0,1]^{2}$ and $\hat{\theta}^{2} \in[0,1]$.

I say that a decision rule $q(\theta)$ is implementable by a sequential mechanism if there exists a transfer function $t(\theta)$ such that $(q(\theta), t(\theta))$ is implementable by a sequential mechanism.

Consider the following set of decreasing functions $C:=\{C:[0,1] \rightarrow[0,1]$ s.t. $C$ is decreasing $\}$. For each $C \in \mathrm{C}$, I denote $\underline{\theta}^{1, C}:=\inf \left\{\theta^{1}\right.$ s.t. $\left.C\left(\theta^{1}\right)<1\right\}$ and $\bar{\theta}^{1, C}:=\sup \left\{\theta^{1}\right.$ s.t. $\left.C\left(\theta^{1}\right)>0\right\} .^{6}$

Theorem 2 A decision rule $q(\theta)$ is implementable by a sequential mechanism if and only if there exists a function $C \in \mathrm{C}$ such that

$$
q(\theta)= \begin{cases}1 \text { if } & \theta^{2}>C\left(\theta^{1}\right) \\ 0 \text { or } 1 \text { if } & \theta^{2}=C\left(\theta^{1}\right) \\ 0 & \text { otherwise }\end{cases}
$$

and in addition $V\left(\theta^{1}, C\left(\theta^{1}\right)\right)$ is a decreasing function of $\theta^{1}$ in the segment ${ }^{7}$ $\left[\underline{\theta}^{1, C}, \bar{\theta}^{1, C}\right] \cdot 8$

\footnotetext{
$\overline{{ }^{6} \text { Note that under the functions } C}\left(\theta^{1}\right)=1$ and $C\left(\theta^{1}\right)=0$ one of the terms $\underline{\theta}^{1, C}$ or $\bar{\theta}^{1, C}$ does not exist, as one of the above sets is empty. However, in these cases the decision rules that correspond to these functions are constant and therefore implementable.

${ }^{7}$ For every $\theta^{1}<\underline{\theta}^{1, C}$ we have $C\left(\theta^{1}\right)=1$ and $q\left(\theta^{1}, 1\right)=0$. For every $\bar{\theta}^{1, C}<\theta^{1}$ we have $C\left(\theta^{1}\right)=0$ and $q\left(\theta^{1}, 0\right)=1$. That is, for these $\theta^{1}$ the decision rule $q\left(\theta^{1}, \cdot\right)$ is a constant function.

8 The characterization of Theorem 2 holds in any environment where $V$ is increasing in $\theta^{1}$ and $\theta^{2}$, and where the effects of $\theta^{1}$ on $V$ and on $F\left(\theta^{2} \mid \theta^{1}\right)$ constitute a surrounding where higher types in the first period are facing higher probabilities of receiving higher valuations.
} 
In the standard formulation of the sequential screening model à la Courty and Li (2000), which describes how the first-period signal affects the conditional distribution of the buyer's realized valuation, i.e., where $V\left(\theta^{1}, \theta^{2}\right)=\theta^{2}$, Krähmer and Strausz (2011) characterize the set of implementable deterministic mechanisms. ${ }^{9}$ Under this formulation, we get that any decision rule with a decreasing threshold function $C\left(\theta^{1}\right) \in \mathrm{C}$ is implementable by a sequential mechanism. Theorem 2 reestablish their result in the paper's formulation of the sequential screening model, that explicitly accounts for the payoff effect of the buyer's signals. Under this formulation, the necessary and sufficient condition for implementation translates to the following condition: the threshold function $C\left(\theta^{1}\right) \in \mathrm{C}$ is decreasing and $V\left(\theta^{1}, C\left(\theta^{1}\right)\right)$ is a decreasing function of $\theta^{1}$.

The argument for this result is as follows. Assume the buyer reports her first type $\theta^{1}$ truthfully. Then in the second period we are facing an implementation problem with respect to a unidimensional signal $\theta^{2}$, where the buyer's valuation is $V\left(\theta^{1}, \theta^{2}\right)$. Since $V$ is strictly monotone in $\theta^{2}$, implementability holds if and only if the decision rule is monotonic with respect to $\theta^{2}$. The threshold is set at $C\left(\theta^{1}\right)$ and the payment to the seller in case of a sale is

$$
\tau\left(\theta^{1}\right):= \begin{cases}V\left(\theta^{1}, C\left(\theta^{1}\right)\right) & \text { if } \underline{\theta}^{1, C} \leq \theta^{1} \leq \bar{\theta}^{1, C} \\ V\left(\bar{\theta}^{1, C}, 0\right) & \text { if } \bar{\theta}^{1, C}<\theta^{1} \leq 1\end{cases}
$$

This implies that each report of $\theta^{1}$ in the first period sets a price for the item in the second period. In addition, the buyer is charged a fee $p\left(\theta^{1}\right)$ for participating in the mechanism that sets the price $\tau\left(\theta^{1}\right)$. Thus, the transfer function is set as

$$
t(\theta)= \begin{cases}p\left(\theta^{1}\right)+\tau\left(\theta^{1}\right) & \text { if } q(\theta)=1 \\ p\left(\theta^{1}\right) & \text { if } q(\theta)=0\end{cases}
$$

We get that an implementable sequential mechanism provides the buyer in the first period with a menu of options, each sets a strike price, $\tau\left(\theta^{1}\right)$, for the item in the second period. All types of the buyer agree on the ordinal order of these strike prices: the lower the strike price, the better. However, they differ in the intensity of their preferences, such that higher $\theta^{1}$ types are more willing to pay for lower strike prices. In such a single crossing environment a necessary and sufficient condition for implementation is that higher types are assigned with lower strike prices, i.e., the property that $\tau\left(\theta^{1}\right)$ is decreasing is necessary and sufficient for implementation.

I now present the necessary and sufficient conditions for implementation in both static and sequential environments in terms of the variation of the buyer's valuation along the boundary of the decision rule. Without loss of generality I restrict attention to the set of decision rules that are monotonic with respect to each of the buyer's signals, and denote this set by $\mathscr{D}$. Each decision rule in $\mathscr{D}$ is identified with a function $C \in \mathrm{C}$ that maps each type in $\left[\underline{\theta}^{1, C}, \bar{\theta}^{1, C}\right]$ to a threshold type in the second period. I denote the

\footnotetext{
9 See Lemma 6 in Krähmer and Strausz (2011).
} 
Fig. 1 The buyer's valuation decreases along the boundary of the decision rule

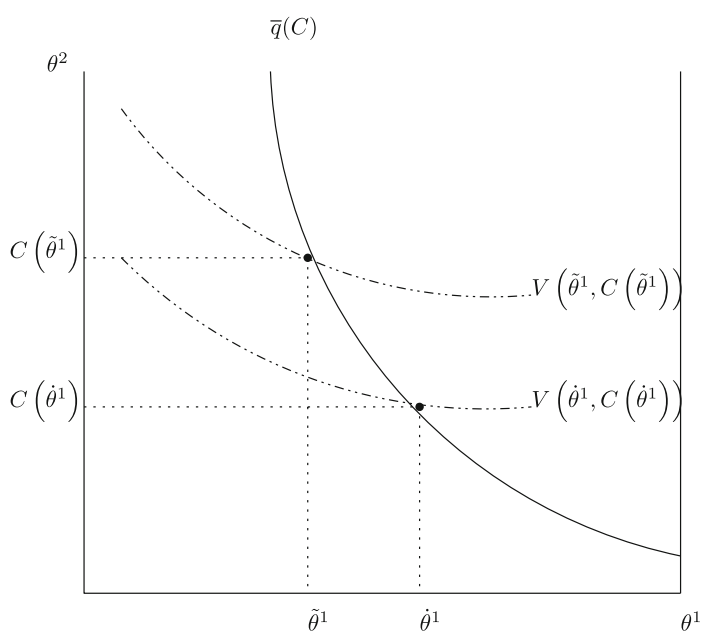

boundary of a decision rule $q(\theta) \in \mathscr{D}$ by $\bar{q}(C)$, i.e., $\bar{q}(C):=\left(\theta^{1}, C\left(\theta^{1}\right)\right)_{\theta^{1} \in\left[\underline{\theta}^{1, C}, \bar{\theta}^{1, C}\right]}$ where $C \in \mathrm{C}$. Using the above characterizations I reach the following conclusion:

Corollary 3 A decision rule $q(\theta) \in \mathscr{D}$ with a boundary $\bar{q}(C)$ is implementable by a static mechanism if and only if for any $\tilde{\theta}^{1}<\dot{\theta}^{1} \in\left[\underline{\theta}^{1, C}, \bar{\theta}^{1, C}\right]$ we have

$$
V\left(\tilde{\theta}^{1}, C\left(\tilde{\theta}^{1}\right)\right)=V\left(\dot{\theta}^{1}, C\left(\dot{\theta}^{1}\right)\right)
$$

and it is implementable by a sequential mechanism if and only if for any $\tilde{\theta}^{1}<\dot{\theta}^{1} \in$ $\left[\underline{\theta}^{1, C}, \bar{\theta}^{1, C}\right]$ we have

$$
V\left(\tilde{\theta}^{1}, C\left(\tilde{\theta}^{1}\right)\right) \geq V\left(\dot{\theta}^{1}, C\left(\dot{\theta}^{1}\right)\right)
$$

In words, a decision rule is implementable by a static mechanism if and only if its boundary coincides with one of the buyer's isovalue curves and is implementable by a sequential mechanism if and only if the buyer's valuation weakly decreases as we move rightward along its boundary. Figure 1 illustrates the case where the buyer's valuation satisfies the condition of Corollary 3 .

Remark In an implementable sequential mechanism higher types in the first period are facing higher expected utilities. Therefore, individual rationality is satisfied whenever the lowest type in the first period is willing to participate in the mechanism. For example, when the price for the option that offers the highest strike price in the second period is zero. 


\section{Efficiency}

This paper considers a seller whose objective is to implement efficiency, namely, who wants to implement the allocation that would produce the greatest social welfare. In situations where the buyer's information affects the social welfare only by its effect on the buyer's valuation, efficiency is implementable in static environments. When there are informational externalities on the social welfare, the possibility of implementing efficiency in static settings depends on the dimensionality of the information. When the buyer's information is unidimensional, efficiency is implementable if a singlecrossing condition is satisfied, see, for example, Cremer and McLean (1985), Maskin (1992), Dasgupta and Maskin (2000), Jehiel and Moldovanu (2001), and Perry and Reny (2002). If, however, the buyer's information is multidimensional, then it is typically impossible to implement efficiency, see, Maskin (1992), Dasgupta and Maskin (2000), and Jehiel and Moldovanu (2001). In this section, I show that in sequential environments efficiency can be implemented even in the latter case.

I consider efficient decision rules, which I denote by $q^{e}$, that take the following form. There exists a function $U:[0,1]^{2} \rightarrow \mathbb{R}$ such that

$$
q^{e}(\theta)= \begin{cases}1 \text { if } & U\left(\theta^{1}, \theta^{2}\right)>C \\ 0 \text { or } 1 \text { if } & U\left(\theta^{1}, \theta^{2}\right)=C \\ 0 & \text { otherwise }\end{cases}
$$

where $C \in \mathbb{R}$ and $U\left(\theta^{1}, \theta^{2}\right)$ is continuously differentiable and strictly increasing in $\theta^{1}$ and $\theta^{2}$. I define the set $\bar{U}$ to be the boundary of the efficient decision rule, i.e., $\bar{U}:=\left\{\left(\theta^{1}, \theta^{2}\right)\right.$ s.t. $\left.U\left(\theta^{1}, \theta^{2}\right)=C\right\}$. I denote by $[\underline{u}, \bar{u}]$ the segment of all $\theta^{1}$ such that there exists $\theta^{2}$ where $\left(\theta^{1}, \theta^{2}\right) \in \bar{U}$. I define $\tilde{\theta}^{2}\left(\theta^{1}\right)$ to be the function that assigns to any $\theta^{1} \in[\underline{u}, \bar{u}]$ the threshold type it inflicts with respect to $\theta^{2}$, i.e., $\tilde{\theta}^{2}\left(\theta^{1}\right):=\theta^{2}$ s.t. $\left(\theta^{1}, \theta^{2}\right) \in \bar{U}$. Using the results of Sect. 3 , I deduce the main result of the paper.

Proposition 4 The efficient decision rule $q^{e}(\theta)$ is implementable by a static mechanism if and only if

$$
\frac{\partial V / \partial \theta^{1}}{\partial V / \partial \theta^{2}}\left(\theta^{1}, \theta^{2}\right)=\frac{\partial U / \partial \theta^{1}}{\partial U / \partial \theta^{2}}\left(\theta^{1}, \theta^{2}\right)
$$

for every $\left(\theta^{1}, \theta^{2}\right) \in \bar{U}$, and is implementable by a sequential mechanism if and only if

$$
\frac{\partial V / \partial \theta^{1}}{\partial V / \partial \theta^{2}}\left(\theta^{1}, \theta^{2}\right) \leq \frac{\partial U / \partial \theta^{1}}{\partial U / \partial \theta^{2}}\left(\theta^{1}, \theta^{2}\right)
$$

for every $\left(\theta^{1}, \theta^{2}\right) \in \bar{U}$.

Proposition 4 follows from the following argument. The boundary of the efficient decision rule coincides with one of the buyer's isovalue curves if and only if the 
marginal rates of substitutions of $V(\theta)$ and $U(\theta)$ are equal for every $\left(\theta^{1}, \theta^{2}\right) \in \bar{U}$. The buyer's valuation weakly decreases as we move rightward along the boundary of the efficient decision rule if and only if the marginal rates of substitutions of $V(\theta)$ are weakly smaller than those of $U(\theta)$ for every $\left(\theta^{1}, \theta^{2}\right) \in \bar{U}$. Therefore, by Corollary 3 , we get that the efficient decision rule is implementable by a static mechanism if and only if the first condition of Proposition 4 holds, and is implementable by a sequential mechanism if and only if the second condition of Proposition 4 holds. The necessary and sufficient condition for efficient static implementation is the manifestation of Jehiel and Moldovanu (2001) congruence condition in the seller-buyer environment of this paper. The necessary and sufficient condition for efficient sequential implementation is a novel contribution of the paper. In Sect. 4.1, I discuss applications in which the difference between the conditions enables an efficient implementation in a sequential environment but not in a static environment.

I now consider the case where $\frac{\partial V / \partial \theta^{1}}{\partial V / \partial \theta^{2}}\left(\theta^{1}, \theta^{2}\right) \geq \frac{\partial U / \partial \theta^{1}}{\partial U / \partial \theta^{2}}\left(\theta^{1}, \theta^{2}\right)$, i.e., the buyer's valuation is increasing along the boundary of the efficient decision rule. First note that the aforementioned inequality is equivalent to $\frac{\partial V / \partial \theta^{2}}{\partial V / \partial \theta^{1}}\left(\theta^{1}, \theta^{2}\right) \leq \frac{\partial U / \partial \theta^{2}}{\partial U / \partial \theta^{1}}\left(\theta^{1}, \theta^{2}\right)$, i.e., when $\theta^{2}$ arrives in period 1 and $\theta^{1}$ arrives in period 2 the buyer's valuation is decreasing along the boundary of the efficient decision rule. This implies:

Corollary 5 If the seller controls the order of the buyer's signals, then the monotonicity of the buyer's valuation along the boundary of the efficient decision rule (increasing or decreasing) is a necessary and sufficient condition for implementing efficiency.

I now consider the case where the buyer's valuation is increasing along the boundary of the efficient decision rule and the seller cannot control the order in which the buyer's signals arrive. I show that in this case the social welfare does not increase from applying sequential mechanisms, ${ }^{10}$ i.e., the second-best mechanism in the sequential setting provides the same expected social welfare as the second-best mechanism in the static setting. ${ }^{11}$ That is, in a sequential environment, when the buyer's signals do not arrive at the right order, then not only that full efficiency cannot be implemented but the sequential arrival of the buyer's signals does not even improve the second-best outcome.

Theorem 6 Assume that $\frac{\partial V / \partial \theta^{1}}{\partial V / \partial \theta^{2}}\left(\theta^{1}, \theta^{2}\right)>\frac{\partial U / \partial \theta^{1}}{\partial U / \partial \theta^{2}}\left(\theta^{1}, \theta^{2}\right)$ for every $\left(\theta^{1}, \theta^{2}\right) \in \bar{U}$. In a sequential environment, there exists a second-best decision rule that sets a single price for the item in the second period, i.e., $\tau\left(\theta^{1}\right)=\tau$. This decision rule is implementable in a static environment.

Proof I show in "Appendix C" that there exists a second-best sequential mechanism whose boundary intersects with the boundary of the efficient decision rule, i.e., there exists a type $\tilde{\theta}^{1} \in[\underline{u}, \bar{u}]$ for which $\tau\left(\tilde{\theta}^{1}\right)=V\left(\tilde{\theta}^{1}, \tilde{\theta}^{2}\left(\tilde{\theta}^{1}\right)\right)$. Let's consider this mechanism. For every $\theta^{1}<\tilde{\theta}^{1}$, sequential implementability implies that $\tau\left(\theta^{1}\right) \geq \tau\left(\tilde{\theta}^{1}\right)$. For any $\operatorname{such} \theta^{1}$, if $\tau\left(\theta^{1}\right)>\tau\left(\tilde{\theta}^{1}\right)$, then

\footnotetext{
10 I still restrict attention to deterministic mechanisms.

11 A second-best mechanism is a mechanism that maximizes the social welfare subjected to incentive compatibility constraints.
} 
Fig. 2 Social welfare does not improve from the sequential arrival of the buyer's signals

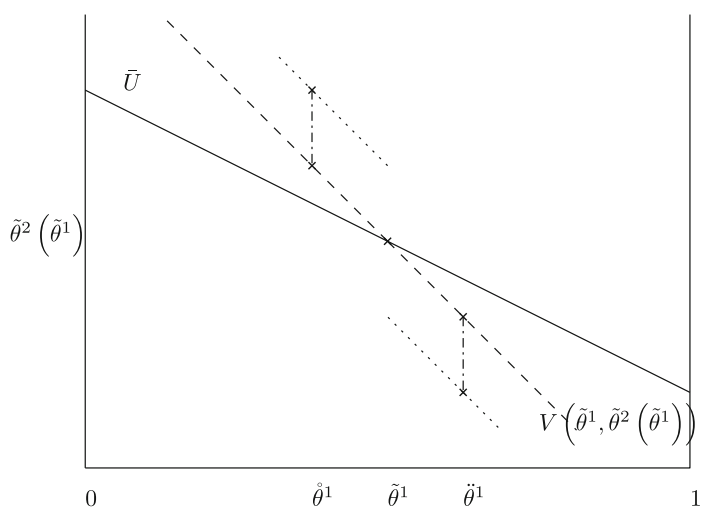

$\left\{\theta_{2}\right.$ s.t. $\left.V\left(\theta^{1}, \theta^{2}\right) \geq \tau\left(\theta^{1}\right)\right\}$, the set of signals for which a sale is executed, is strictly contained in $\left\{\theta_{2}\right.$ s.t. $\left.V\left(\theta^{1}, \theta^{2}\right) \geq \tau\left(\tilde{\theta}^{1}\right)\right\}$, the set of signals for which a sale would have been executed if the price had been $\tau\left(\tilde{\theta}^{1}\right)$. Since the MRS of $V$ is steeper than the MRS of $U$, these two sets are contained in $\left\{\theta_{2}\right.$ s.t. $\left.U\left(\theta^{1}, \theta^{2}\right) \geq C\right\}$, the set of signals for which a sale should be executed according to the efficient decision rule. Therefore, if $\tau\left(\theta^{1}\right)>\tau\left(\tilde{\theta}^{1}\right)$, then the set of signals where a sale does not happen but should happen increases with respect to the case where $\tau\left(\theta^{1}\right)=\tau\left(\tilde{\theta}^{1}\right)$ and the expected social welfare decreases. For every $\theta^{1}>\tilde{\theta}^{1}$ sequential implementability implies that $\tau\left(\theta^{1}\right) \leq \tau\left(\tilde{\theta}^{1}\right)$. For any such $\theta_{1}$, if $\tau\left(\theta^{1}\right)<\tau\left(\tilde{\theta}^{1}\right)$ then $\left\{\theta^{2}\right.$ s.t. $\left.V\left(\theta^{1}, \theta^{2}\right) \geq \tau\left(\theta^{1}\right)\right\}$ strictly contains the set $\left\{\theta^{2}\right.$ s.t. $\left.V\left(\theta^{1}, \theta^{2}\right) \geq \tau\left(\tilde{\theta}^{1}\right)\right\}$ and since the MRS of $V$ is steeper than the MRS of $U$ these two sets contain the set $\left\{\theta^{2}\right.$ s.t. $\left.U\left(\theta^{1}, \theta^{2}\right) \geq C\right\}$. Therefore, if $\tau\left(\theta^{1}\right)<\tau\left(\tilde{\theta}^{1}\right)$ then the set of signals where a sale does happen but should not happen increases with respect to the case where $\tau\left(\theta^{1}\right)=\tau\left(\tilde{\theta}^{1}\right)$ and the expected social welfare decreases. We conclude that there exists a second-best mechanism that sets a single price for the item in the second period. Such a mechanism is also implementable in a static environment; hence, the social welfare cannot increase from applying sequential mechanisms.

The above argument is illustrated in Fig. 2. The area above (below) the solid line is where a sale is efficient (inefficient). If $\tau\left(\theta^{1}\right)=\tau\left(\tilde{\theta}^{1}\right)$ for every $\theta^{1}$, then a sale occurs for every signal in the area above the dashed line. If for types $\dot{\theta}^{1}<\tilde{\theta}^{1}$ we have $\tau\left(\dot{\theta}^{1}\right)>\tau\left(\tilde{\theta}^{1}\right)$, then a sale occurs for every signal in the area above the dotted line, and the intersection of the area where the sale is efficient and the area where the sale is carried out decreases. If for types $\tilde{\theta}^{1}<\ddot{\theta}^{1}$ we have $\tau\left(\tilde{\theta}^{1}\right)>\tau\left(\ddot{\theta}^{1}\right)$, then the intersection of the area where the sale is inefficient and the area where the sale is carried out increases. 


\subsection{Applications}

In this subsection, I present various applications where the seller's ability to control the order in which the buyer's signals arrive facilitates his ability to implement an efficient sale. Corollary 5 implies that in such cases the seller can implement an efficient sale by a sequential mechanism if and only if the buyer's valuation moves monotonically along the efficient decision rule's boundary. In a static setting, Proposition 4 implies that the seller can implement an efficient sale if and only if the buyer's valuation is constant along the efficient decision rule's boundary.

\section{Efficient privatization}

A government is considering whether to use an oil field independently and to receive social welfare of $C$, or to sell it to a private firm that would then be a monopoly in the market. The demand is commonly known. The firm's costs are revealed by tests conducted by the firm. I denote the firm's marginal cost by $\theta^{1}$, and its fixed cost by $\theta^{2}$. The social welfare in case of a sale, denoted by $U\left(\theta^{1}, \theta^{2}\right)$, takes into account the positive effect of a reduction in the marginal cost both on the firm's profit, denoted by $V\left(\theta^{1}, \theta^{2}\right)$, and on the consumer surplus and so we have that $\partial V / \partial \theta^{1}\left(\theta^{1}, \theta^{2}\right)<\partial U / \partial \theta^{1}\left(\theta^{1}, \theta^{2}\right)$. Since the consumer surplus is not affected by a decrease in the fixed cost we have that $\partial V / \partial \theta^{2}\left(\theta^{1}, \theta^{2}\right)=\partial U / \partial \theta^{2}\left(\theta^{1}, \theta^{2}\right)$. We conclude that $\frac{\partial V / \partial \theta^{1}}{\partial V / \partial \theta^{2}}\left(\theta^{1}, \theta^{2}\right)<\frac{\partial U / \partial \theta^{1}}{\partial U / \partial \theta^{2}}\left(\theta^{1}, \theta^{2}\right)$ for every $\left(\theta^{1}, \theta^{2}\right) \in[0,1]^{2}$, i.e., the profit of the firm is strictly decreasing along the boundary of the efficient decision rule. This implies that the efficient sale is not implementable by a static mechanism and is implementable by a sequential mechanism. ${ }^{12}$

\section{Choosing an optimal project}

A board of directors needs to decide upon one of two possible projects, $a$ and $b$, to maximize its firm's profits. The task of gathering information about the profitability of each project is delegated to the firm's CEO. The CEO prefers project $a$ to $b$ but the intensity of his preferences depends on the profitability of the projects. In particular, her valuation for project $a$ is $v_{a}=f\left(\theta_{1}\right)$ and for project $b$ is $v_{b}=g\left(1-\theta_{2}\right)$, where $\theta_{1}$ is the profitability of project $a$ and $1-\theta_{2}$ is the profitability of project $b$ and $f>g>0$. I assume that $\theta_{i} \in[0,1]$ for $i \in\{1,2\}$, that $f$ and $g$ are differentiable, and that either $f^{\prime} \geq g^{\prime}>0$ or $0<f^{\prime}<g^{\prime}$. The efficient decision rule's boundary is the set of pairs $\left\{\left(\theta_{1}, 1-\theta_{1}\right)\right\}_{\theta_{1} \in[0,1]}$ and its marginal rate of substitution between $\theta_{1}$ and $\theta_{2}$ is $1 .^{13}$ The implementation problem is equivalent to the one discussed in the paper, when the buyer's valuation function is taken to be $V\left(\theta^{1}, \theta^{2}\right)=f\left(\theta_{1}\right)-g\left(1-\theta_{2}\right)$. Therefore, the efficient decision rule is implementable by a static mechanism if and

\footnotetext{
12 The above example generalizes to the set of cases where a government needs to decide whether a private firm should join an oligopolistic market, where only the marginal cost affects the equilibrium price, which in turn affects the profits of other firms and the consumer surplus.

${ }^{13}$ I assume that the monetary transfers to the CEO in the mechanism are negligible and therefore the first-best decision rule is exogenous.
} 
only if $\frac{f^{\prime}\left(\theta_{1}\right)}{g^{\prime}\left(\theta_{1}\right)}=1$ for every $\theta_{1} \in[0,1]$. This condition is met only for a set of functions of measure zero, and so implementing efficiency in a static environment is generically impossible. However, $V$ is monotonic along the efficient decision rule's boundary for any pair of functions $(f, g)$, i.e., the efficient decision rule is always implementable by a sequential mechanism.

\section{Efficient allocation with interdependent valuations}

A seller of an item faces two potential buyers, A and B, and wants to allocate it to the buyer who values it the most. Both buyers' valuations depend on two signals, $\theta^{1}$ and $\theta^{2}$, but only buyer A observes the realizations of these signals. The buyers' valuation functions are drawn from a set of functions that are ordered in the following two ways. The first is that for every two functions, and every realization of signals, the partial derivatives of one function are bigger than the partial derivatives of the other. ${ }^{14}$ The second is that for every two functions, and every realization of signals, one has a weakly smaller MRS than the other. Buyer A is assigned the valuation that has the higher partial derivatives. An implication of the impossibility result of Jehiel and Moldovanu (2001) is that it is generically impossible to implement the efficient allocation by a static mechanism. However, the above assumptions imply that buyer A's valuation is monotonic along the efficient decision rule's boundary; i.e., the efficient allocation is always implementable by a sequential mechanism.

\section{Discussion}

I have considered the problem of efficient allocation of a single item in environments with two periods where the buyer receives a uni-dimensional signal in each period. I presented a novel condition on the relationship between the buyer's valuation and the social welfare that is necessary and sufficient for efficient implementation. This condition shows that, in sequential environments, efficiency can be implemented even in the presence of informational externalities. This result, together with the impossibility result on efficient implementation in the presence of informational externalities in static environments, implies that a benevolent seller can benefit from strategically scheduling the buyer's information to the extent that he attains full efficiency.

A straightforward way to extend the analysis in this paper to the case of multiple buyers is to define a notion of ex-post implementation by a sequential mechanism that requires that the conditions of sequential implementation in the single buyer case would hold for every buyer, for every realization of signals of the other buyers. The set of expost implementable decision rules in the multiple buyers case is characterized as the set of decision rules for which the necessary and sufficient conditions for implementation in the single-buyer case apply for every buyer for every realization of signals of the other buyers.

This paper analyzes efficient implementation in a special yet canonical twoalternative two-period setting. In this setting, the implementability of deterministic

\footnotetext{
14 This is a generalization of the single crossing property in the case of a uni-dimensional signal, see Dasgupta and Maskin (2000).
} 
mechanisms is characterized by a simple monotonicity condition. ${ }^{15}$ A question that arises is to what extent a simple characterization can be attained in more general environments. In a dynamic environment, the agent's report in an early period affects the allocations and transfers in future periods. Therefore, the incentive compatibility problem in an early period is equivalent to the incentive compatibility problem in a static unidimensional environment with multiple allocations. Incentive compatibility in these environments typically cannot be characterized by a simple condition. The reason for the simple characterization of incentive compatibility in the environment of the paper is the following. In each period, the type-space satisfies single-crossing; i.e., the agent's types share the same ordinal preferences over any set of alternatives that the mechanism offers in that period, and higher types have higher willingness-to-pay for better alternatives. The environment of the paper is unique in the sense that the endogenous allocations that arise in the first period result in a single-crossing structure. In more general environments, however, such a single-crossing structure typically does not arise. Indeed, in dynamic environments with stochastic mechanisms and/or more than two alternatives and/or more than two periods, the static problem in an early period of the mechanism does not entail a single-crossing structure. In the absence of single-crossing, the mechanism design literature offers more general and abstract characterizations, e.g., "cyclic monotonicity" in static settings (Rochet 1987), and "integral monotonicity" in dynamic settings (Pavan et al. 2014). However, these characterizations involve conditions that are hard to verify and hard to work with. Thus, characterizing efficient implementation in more general environments would involve less tractable conditions.

Funding Open Access funding enabled and organized by Projekt DEAL.

Open Access This article is licensed under a Creative Commons Attribution 4.0 International License, which permits use, sharing, adaptation, distribution and reproduction in any medium or format, as long as you give appropriate credit to the original author(s) and the source, provide a link to the Creative Commons licence, and indicate if changes were made. The images or other third party material in this article are included in the article's Creative Commons licence, unless indicated otherwise in a credit line to the material. If material is not included in the article's Creative Commons licence and your intended use is not permitted by statutory regulation or exceeds the permitted use, you will need to obtain permission directly from the copyright holder. To view a copy of this licence, visit http://creativecommons.org/licenses/by/4.0/.

\section{Appendix}

\section{A Second-best analysis}

In this appendix, I analyze the case where the buyer's valuation is not monotonic along the boundary of the efficient decision rule. I present sufficient conditions for the second-best solution to provide a higher expected social welfare in a sequential environment than in a static environment. The improvement upon the static second-best mechanism is achieved through the construction of a decision rule whose boundary differs from the boundary of the static second-best decision rule in a way that provides

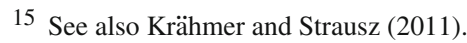


a welfare-improving allocation while maintaining sequential implementability. Consider the second-best decision rule of the static environment. I denote it by $q^{S B}(\theta)$. This decision rule takes the form of

$$
q^{S B}(\theta)= \begin{cases}1 \text { if } & V\left(\theta^{1}, \theta^{2}\right)>C^{S B} \\ 0 \text { or } 1 \text { if } & V\left(\theta^{1}, \theta^{2}\right)=C^{S B} \\ 0 & \text { otherwise }\end{cases}
$$

I denote by $\bar{V}^{S B}$ the boundary of the second-best static decision rule $q^{S B}(\theta)$, i.e.,

$$
\bar{V}^{S B}:=\left\{\left(\theta^{1}, \theta^{2}\right) \text { s.t. } V\left(\theta^{1}, \theta^{2}\right)=C^{S B}\right\}
$$

Note that the boundary of the second-best static decision rule $\bar{V}^{S B}$ and the boundary of the efficient decision rule $\bar{U}$ intersect. ${ }^{16}$ I denote by $\dot{\theta}^{1}$ the rightmost point at which these boundaries intersect, i.e.,

$$
\dot{\theta}^{1}:=\max \left\{\theta^{1} \text { s.t. }\left(\theta^{1}, \tilde{\theta}^{2}\left(\theta^{1}\right)\right) \in \bar{V}^{S B} \cap \bar{U}\right\}
$$

I denote by $\ddot{\theta}^{1}$ the leftmost point at which these boundaries intersect, i.e.,

$$
\ddot{\theta}^{1}:=\min \left\{\theta^{1} \text { s.t. }\left(\theta^{1}, \tilde{\theta}^{2}\left(\theta^{1}\right)\right) \in \bar{V}^{S B} \cap \bar{U}\right\}
$$

I now present sufficient conditions for improving the second-best solution by a sequential mechanism.

Theorem 7 Assume one of the following conditions holds: (1) for every $\theta^{1}>\dot{\theta}^{1}$ we have that $V\left(\dot{\theta}^{1}, \tilde{\theta}^{2}\left(\dot{\theta}^{1}\right)\right)>V\left(\theta^{1}, \tilde{\theta}^{2}\left(\theta^{1}\right)\right)$ or (2) for every $\theta^{1}<\ddot{\theta}^{1}$ we have that $V\left(\theta^{1}, \tilde{\theta}^{2}\left(\theta^{1}\right)\right)>V\left(\ddot{\theta}^{1}, \tilde{\theta}^{2}\left(\ddot{\theta}^{1}\right)\right)$. Then there exists a decision rule that is sequentially implementable and provides a higher expected welfare than $q^{S B}(\theta)$.

The idea of the proof is as follows. Assume for example that (1) holds. This means that at any point that is to the right of $\dot{\theta}^{1}$, the boundary of the second-best static decision rule lies above the boundary of the efficient decision rule. Therefore, we can construct a decision rule $\tilde{q}(\theta)$ with two properties. The first is that to the left of $\dot{\theta}^{1}$ the boundary of the decision rule $\tilde{q}(\theta)$ coincides with the boundary of $q^{S B}(\theta)$, while to the right of $\dot{\theta}^{1}$ the boundary of the decision rule $\tilde{q}(\theta)$ is below the boundary of $q^{S B}(\theta)$ and above the boundary of the efficient decision rule. This property implies that $\tilde{q}(\theta)$ provides a higher expected welfare than $q^{S B}(\theta)$. The second property is that the buyer's valuation is decreasing as we move rightward along the boundary of $\tilde{q}(\theta)$. This property implies that $\tilde{q}(\theta)$ is sequentially implementable. Such a construction is illustrated in the Fig. 3.

\footnotetext{
16 In "Appendix B", I characterize the second-best mechanism in a static environment and show that this property holds.
} 
Fig. 3 The set where $q^{S B}(\theta)$ and $\tilde{q}(\theta)$ do not coincide is denoted by $\mathrm{E}$

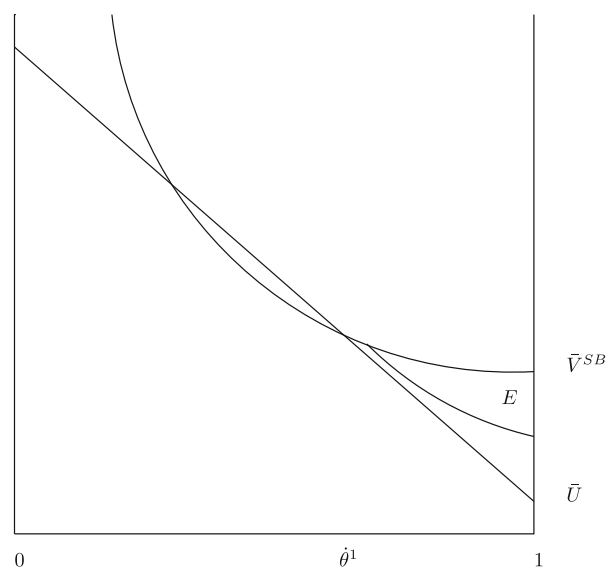

\section{B Generality of the results}

In the present paper, I have restricted attention to direct deterministic mechanisms. In this appendix I analyze for which results of this paper this restriction is without loss of generality. I consider two generalizations. The first is to the set of indirect deterministic mechanisms. In an indirect deterministic mechanism if agents play mixed strategies then the direct mechanism, that mimics the equilibrium strategies of the indirect mechanism, is not deterministic, see, e.g., Strausz (2003), Jarman and Meisner (2017), and Chen et al. (2019). I find that all the results of the paper still hold even if we consider indirect deterministic mechanisms. This outcome is based on the observation that for every implementable indirect deterministic mechanism there exists an implementable direct deterministic mechanism that yields equal or greater social welfare.

An implementable deterministic static mechanism yields two alternatives to the buyer (buy the item or don't buy the item) and assigns to each alternative a single price. Therefore, the only set of signals where the buyer can be indifferent between the two alternatives (and play mixed strategies) is the isovalue curve where the buyer's valuation equals the difference in transfers. This set is of measure zero and does not affect the expected social welfare. Hence, a direct mechanism that arbitrarily assigns to the signals in this set a single alternative yields the same expected welfare. An implementable sequential deterministic mechanism yields two alternatives in the second period (buy the item or don't buy the item) and assigns to each alternative a single price. Therefore, there is a single signal in the second period where the buyer can be indifferent between the two alternatives. Of course, allowing for mixed strategies at this point would not change the expected social welfare. In the first period of an implementable sequential deterministic mechanism every type of the buyer may randomize between several options that this type is indifferent among. Each option is composed of a single price in the second period and a payment today. Denote by $I\left(\theta^{1}\right)$ the support of options that type $\theta^{1}$ is mixing. Implementability implies that every $a \in I\left(\theta^{1}\right)$ is preferred by type $\theta^{1}$ to every $b \in I\left(\tilde{\theta}^{1}\right)$ and every $b \in I\left(\tilde{\theta}^{1}\right)$ is preferred by type $\tilde{\theta}^{1}$ to every $a \in I\left(\theta^{1}\right)$. Therefore, every mechanism that offers 
some arbitrary $a$ in $I\left(\theta^{1}\right)$ to type $\theta^{1}$ is implementable by a direct mechanism. Now, each second-period price sets an expected social welfare given $\theta^{1}$. Consider the option $a^{*}\left(\theta^{1}\right) \in I\left(\theta^{1}\right)$ that sets the second-period price that maximizes this expected social welfare given $\theta^{1}$ out of all the options $\operatorname{in}^{17} I\left(\theta^{1}\right)$. The deterministic mechanism for which $a^{*}\left(\theta^{1}\right)=I\left(\theta^{1}\right)$ yields equal or greater expected welfare than the original mechanism and is implementable by a direct mechanism.

The second generalization is to stochastic mechanisms. ${ }^{18}$ A deterministic decision rule is implementable by a stochastic mechanism if and only if it is implementable by a deterministic mechanism. Since efficient decision rules are (almost everywhere) deterministic, all the result about the possibility of implementing full efficiency are without loss of generality. I now show that the second-best decision rule in a static environment is also deterministic. This implies that Theorem 7 is without loss of generality. Denote the valuation of the seller if he keeps the item by $V_{s}$ and the valuation of the buyer if she gets the item by $V_{b}$. I assume that the following condition holds: $V_{b}\left(\theta^{\prime}\right)-V_{b}(\theta)>V_{s}\left(\theta^{\prime}\right)-V_{s}(\theta)$ for every $\theta^{\prime}>\theta$ where $^{19} \theta^{\prime}, \theta \in[0,1]^{2}$. Consider the buyer's isovalue curves in $[0,1]^{2}$ and let

$$
V_{I}(V)=\left\{\theta \in[0,1]^{2} \text { s.t } V_{b}(\theta)=V\right\}
$$

I define the following function:

$$
W(V):=E_{\theta \in V_{I}(V)}\left[V_{b}(\theta)-V_{s}(\theta)\right]
$$

This function is strictly increasing in $V$. I denote by $V^{*}$ the value for which ${ }^{20} W\left(V^{*}\right)=$ 0 . In that case we get that the second-best decision rule out of the set of all stochastic decision rules is

$$
q(\theta)= \begin{cases}1 & \text { if } \theta \in V_{I}(V) \text { s.t. } V>V^{*} \\ r \in[0,1] & \text { if } \theta \in V_{I}\left(V^{*}\right) \\ 0 & \text { if } \theta \in V_{I}(V) \text { s.t. } V<V^{*}\end{cases}
$$

17 Such an option exists because the support of the second-period prices in $I\left(\theta^{1}\right)$ is a closed set. Denote by $I_{h}\left(\theta^{1}\right)$ the set of options in $I\left(\theta^{1}\right)$ that set a price that is greater than or equal to the price that is set Footnote 17 continued

by the efficient decision rule. Denote by $I_{l}\left(\theta^{1}\right)$ the set of options in $I\left(\theta^{1}\right)$ that set a price that is less than or equal to the price that is set by the efficient decision rule. We have that $a^{*}\left(\theta^{1}\right)$ is either the option that sets the minimum price in $I_{h}\left(\theta^{1}\right)$ or the option that sets the maximal price in $I_{l}\left(\theta^{1}\right)$.

18 The restriction to deterministic mechanisms can be justified by practical considerations that derive from the commitment assumption. Laffont and martimort (2002) note that: "Ensuring this verifiability is a more difficult problem than ensuring that a deterministic mechanism is enforced, because any deviation away from a given randomization can only be statistically detected once sufficiently many realizations of the contracts have been observed. [...] The enforcement of such stochastic mechanisms is thus particularly problematic."

19 Let $x^{\prime}>x$ denote that $x^{\prime}$ is at least as large as $x$ in every coordinate and $x^{\prime} \neq x$.

20 If no such value exists then the efficient decision rule is trivial and implementable. 
where $r$ is the probability that the item is assigned to the buyer. That is, the second best decision rule is (almost everywhere) deterministic.

\section{Proofs}

\section{Proof of Claim 1}

Implementability implies that the buyer pays one price if she wins the item, $t(1)$, and another price if she does not win the item, $t(0)$. Let $\theta$ and $\theta^{\prime}$ be two pairs of signals on the same buyer's isovalue curve such that $q(\theta)=1$ and $q\left(\theta^{\prime}\right)=0$; then implementability implies that $V(\theta)-t(1) \geq-t(0)$ and $V\left(\theta^{\prime}\right)-t(1) \leq-t(0)$ and so $V(\theta)=V\left(\theta^{\prime}\right)=t(1)-t(0)$. That is, there can be at most one isovalue curve for which two pairs of signals that lie on this isovalue curve are assigned with different alternatives. This means that the decision rule maps according to values of $V$. Assume that there exists a valuation $V(\theta)$ such that $q(\theta)=1$ and a valuation $V\left(\theta^{\prime}\right)$ such that $q\left(\theta^{\prime}\right)=0$ and $V\left(\theta^{\prime}\right)>V(\theta)$. Implementability implies that $V(\theta)-t(1) \geq-t(0)$ and $V\left(\theta^{\prime}\right)-t(1) \leq-t(0)$ and so we get $V(\theta) \geq V\left(\theta^{\prime}\right)$, a contradiction. This proves necessity. I now prove sufficiency. I set $t(0)=0$ and $t(1)=C$; then we get that for every $\theta$ such that $V(\theta)<C$ we have $V(\theta)-t(1)<0$ and for every $\theta$ such that $V(\theta) \geq C$ we have $V(\theta)-t(1) \geq 0$.

\section{Proof of Theorem 2}

Lemma Condition (ii) in the definition of "implementation by a sequential mechanism" is satisfied iff for every $\theta^{1}$ there exists $C\left(\theta^{1}\right)$ such that

$$
q(\theta)= \begin{cases}1 \text { if } & \theta^{2}>C\left(\theta^{1}\right) \\ 0 \text { or } 1 \text { if } & \theta^{2}=C\left(\theta^{1}\right) \\ 0 & \text { otherwise }\end{cases}
$$

and the transfers $t\left(q(\theta), \theta^{1}\right)+p\left(\theta^{1}\right)$ are set as follows: $t\left(1, \theta^{1}\right)=V\left(\theta^{1}, C\left(\theta^{1}\right)\right)+$ $p\left(\theta^{1}\right)$ and $t\left(0, \theta^{1}\right)=p\left(\theta^{1}\right)$

Proof Consider some $C\left(\theta^{1}\right) \in[0,1]$. If the buyer reports $\theta^{2}>C\left(\theta^{1}\right)$ then she receives a utility of $V\left(\theta^{1}, \theta^{2}\right)-V\left(\theta^{1}, C\left(\theta^{1}\right)\right)-p\left(\theta^{1}\right)$ and if the buyer reports $\theta^{2}<C\left(\theta^{1}\right)$ she receives a utility of $-p\left(\theta^{1}\right)$. By the monotonicity of $V$ we have that if $\theta^{2}>C\left(\theta^{1}\right)$ then $V\left(\theta^{1}, \theta^{2}\right)-V\left(\theta^{1}, C\left(\theta^{1}\right)\right)-p\left(\theta^{1}\right)>-p\left(\theta^{1}\right)$ and if $\theta^{2}<C\left(\theta^{1}\right)$ then $V\left(\theta^{1}, \theta^{2}\right)-V\left(\theta^{1}, C\left(\theta^{1}\right)\right)-p\left(\theta^{1}\right)<-p\left(\theta^{1}\right)$. Assume that the mechanism is incentive compatible in the second period. Then for every $\theta^{2}$ such that $q\left(\theta^{1}, \theta^{2}\right)=1$ we have $V\left(\theta^{1}, \theta^{2}\right) \geq t\left(1, \theta^{1}\right)-t\left(0, \theta^{1}\right)$, and for every $\theta^{2}$ such that $q\left(\theta^{1}, \theta^{2}\right)=0$ we have $V\left(\theta^{1}, \theta^{2}\right) \leq t\left(1, \theta^{1}\right)-t\left(0, \theta^{1}\right)$. Since $V$ is continuous and monotonic there exists a single number $C\left(\theta^{1}\right)$ that satisfies $V\left(\theta^{1}, C\left(\theta^{1}\right)\right)=t\left(1, \theta^{1}\right)-t\left(0, \theta^{1}\right)$. IC 
and the monotonicity of $V$ imply that if $\theta^{2}>C\left(\theta^{1}\right)$ then $q\left(\theta^{1}, \theta^{2}\right)=1$ and if $\theta^{2}<C\left(\theta^{1}\right)$ then $q\left(\theta^{1}, \theta^{2}\right)=0$.

I now proceed to prove that given that the condition in the above Lemma is satisfied, it is necessary and sufficient for implementation that $V\left(\theta^{1}, C\left(\theta^{1}\right)\right):=\tau\left(\theta^{1}\right)$ is a decreasing function of $\theta^{1}$ in the segment $\left[\underline{\theta}^{1, C}, \bar{\theta}^{1, C}\right]$. I show that given the assumptions of the model the set of types of the first period entails a single crossing structure, i.e., all types prefer lower second period prices and higher types are more willing to pay for lower prices. Consider some type $\theta^{1}$ facing a price $\tau$ in the second period, this type's expected valuation is

$$
\int_{V^{-1}\left(\theta^{1}, \tau\right)}^{1}\left(V\left(\theta^{1}, s\right)-\tau\right) f\left(s \mid \theta^{1}\right) d s
$$

this function is decreasing in $\tau$, i.e., all types prefer lower $\tau$ 's. I now move on to show that higher $\theta^{1}$ have higher willingness to pay for lower $\tau$ 's. Consider some type $\theta^{1}$ and two prices $\tau^{\prime}<\tau$ I define the following function

$$
h_{\tau, \tau^{\prime}}\left(\theta^{1}, \theta^{2}\right):= \begin{cases}0 & \text { if } \theta^{2}<V^{-1}\left(\theta^{1}, \tau^{\prime}\right) \\ \left(V\left(\theta^{1}, s\right)-\tau^{\prime}\right) & \text { if } V^{-1}\left(\theta^{1}, \tau^{\prime}\right) \leq \theta^{2} \leq V^{-1}\left(\theta^{1}, \tau\right) \\ \tau-\tau^{\prime} & \text { if } V^{-1}\left(\theta^{1}, \tau\right)<\theta^{2} \leq 1\end{cases}
$$

I now define the function $W T P\left(\theta^{1}, \tau, \tau^{\prime}\right)$ which is type $\theta^{1}$ willingness to pay from moving from price $\tau$ to price $\tau^{\prime}$

$$
W T P\left(\theta^{1}, \tau, \tau^{\prime}\right)=\int_{0}^{1} h_{\tau, \tau^{\prime}}\left(\theta^{1}, s\right) f\left(s \mid \theta^{1}\right) d s
$$

Consider two types $\AA^{1}<\tilde{\theta}^{1}$ we have that $F\left(\theta^{2} \mid \tilde{\theta}^{1}\right)$ strictly first order stochastically dominates $F\left(\theta^{2} \mid \AA^{1}\right)$ and since $h_{\tau, \tau^{\prime}}\left(\theta^{1}, \theta^{2}\right)$ is a non-constant increasing function in $\theta^{2}$ we get that

$$
\int_{0}^{1} h_{\tau, \tau^{\prime}}\left(\stackrel{\circ}{\theta}^{1}, s\right) f\left(s \mid \tilde{\theta}^{1}\right) d s>\int_{0}^{1} h_{\tau, \tau^{\prime}}\left(\stackrel{\circ}{\theta}^{1}, s\right) f\left(s \mid \stackrel{1}{1}^{1}\right) d s
$$

in addition $h_{\tau, \tau^{\prime}}\left(\theta^{1}, \theta^{2}\right)$ is increasing in $\theta^{1}$ and therefore

$$
\int_{0}^{1} h_{\tau, \tau^{\prime}}\left(\tilde{\theta}^{1}, s\right) f\left(s \mid \tilde{\theta}^{1}\right) d s \geq \int_{0}^{1} h_{\tau, \tau^{\prime}}\left(\dot{\theta}^{1}, s\right) f\left(s \mid \tilde{\theta}^{1}\right) d s
$$

we conclude that

$$
W T P\left(\tilde{\theta}^{1}, \tau, \tau^{\prime}\right)>W T P\left(\AA^{1}, \tau, \tau^{\prime}\right)
$$


In the case where $V\left(\theta^{1}, \theta^{2}\right)$ is strictly increasing in $\theta^{1}$ and where $F\left(\theta^{2} \mid \theta^{1}\right)=F\left(\theta^{2}\right)$ we get that $h_{\tau, \tau^{\prime}}\left(\theta^{1}, \theta^{2}\right)$ is a non-constant increasing function in $\theta^{1}$ and so for two types $\AA^{1}<\tilde{\theta}^{1}$ we get that

$$
\int_{0}^{1} h_{\tau, \tau^{\prime}}\left(\tilde{\theta}^{1}, s\right) f(s) d s>\int_{0}^{1} h_{\tau, \tau^{\prime}}\left(\stackrel{\circ}{ }^{1}, s\right) f(s) d s
$$

so in this case we also get

$$
W T P\left(\tilde{\theta}^{1}, \tau, \tau^{\prime}\right)>W T P\left(\stackrel{\theta}{ }^{1}, \tau, \tau^{\prime}\right)
$$

Given that the set of types of the first period entails a single crossing structure the monotonicity of $\tau\left(\theta^{1}\right)$ is necessary and sufficient for implementation (see, Theorem 4.2.5 in Vohra 2011)

\section{Proof of Theorem 6}

I show that there exists a sequential second-best mechanism in which there exists $\tilde{\theta}^{1} \in[\underline{u}, \bar{u}]$ for which $\tau\left(\tilde{\theta}^{1}\right)=V\left(\tilde{\theta}^{1}, \tilde{\theta}^{2}\left(\tilde{\theta}^{1}\right)\right)$. That is, the boundary of the second-best decision rule intersects with the boundary of the efficient decision rule. Consider a mechanism in which there is no $\theta^{1}$ such that $\tau\left(\theta^{1}\right)=V\left(\theta_{1}, \tilde{\theta}_{2}\left(\theta^{1}\right)\right)$. I.e., we are in one of the four following cases:

(a) $\tau\left(\theta^{1}\right)>V\left(\theta^{1}, \tilde{\theta}_{2}\left(\theta^{1}\right)\right)$ for every $\theta^{1} \in[\underline{u}, \bar{u}]$. Consider the price function $\tau^{\prime}\left(\theta_{1}\right)$ :

$$
\tau^{\prime}\left(\theta_{1}\right):= \begin{cases}\tau\left(\theta^{1}\right) & \text { if } \theta^{1}<\bar{u} \\ V\left(\bar{u}, \tilde{\theta}_{2}(\bar{u})\right) & \text { if } \theta^{1} \geq \bar{u}\end{cases}
$$

(b) $\tau\left(\theta^{1}\right)<V\left(\theta^{1}, \tilde{\theta}_{2}\left(\theta^{1}\right)\right)$ for every $\theta^{1} \in[\underline{u}, \bar{u}]$. Consider the price function $\tau^{\prime}\left(\theta_{1}\right)$ :

$$
\tau^{\prime}\left(\theta_{1}\right):= \begin{cases}V\left(\underline{u}, \tilde{\theta}_{2}(\underline{u})\right) & \text { if } \theta^{1} \leq \underline{u} \\ \tau\left(\theta^{1}\right) & \text { if } \theta^{1}>\underline{u}\end{cases}
$$

(c) There exists $\hat{\theta}^{1} \in(\underline{u}, \bar{u})$ such that $\tau\left(\hat{\theta}^{1}\right)>V\left(\hat{\theta}^{1}, \tilde{\theta}^{2}\left(\hat{\theta}^{1}\right)\right)$ and for every $\hat{\theta}^{1}<\theta^{1}$ we have that $\tau\left(\theta^{1}\right)<V\left(\theta^{1}, \tilde{\theta}^{2}\left(\theta^{1}\right)\right)<V\left(\hat{\theta}^{1}, \tilde{\theta}^{2}\left(\hat{\theta}^{1}\right)\right)$. Consider the price function $\tau^{\prime}\left(\theta_{1}\right)$ :

$$
\tau^{\prime}\left(\theta_{1}\right):= \begin{cases}V\left(\hat{\theta}^{1}, \tilde{\theta}_{2}\left(\hat{\theta}^{1}\right)\right) & \text { if } \theta^{1}=\hat{\theta}^{1} \\ \tau\left(\theta^{1}\right) & \text { otherwise }\end{cases}
$$


(d) There exists $\hat{\theta}^{1} \in(\underline{u}, \bar{u})$ such that $\tau\left(\hat{\theta}^{1}\right)<V\left(\hat{\theta}^{1}, \tilde{\theta}^{2}\left(\hat{\theta}^{1}\right)\right)$ and for every $\theta^{1}<\hat{\theta}^{1}$ we have that $V\left(\hat{\theta}^{1}, \tilde{\theta}^{2}\left(\hat{\theta}^{1}\right)\right)<V\left(\theta^{1}, \tilde{\theta}^{2}\left(\theta^{1}\right)\right)<\tau\left(\theta^{1}\right)$. Consider the price function $\tau^{\prime}\left(\theta_{1}\right)$ :

$$
\tau^{\prime}\left(\theta_{1}\right):= \begin{cases}V\left(\hat{\theta}^{1}, \tilde{\theta}^{2}\left(\hat{\theta}^{1}\right)\right) & \text { if } \theta^{1}=\hat{\theta}^{1} \\ \tau\left(\theta^{1}\right) & \text { otherwise }\end{cases}
$$

In all of the four cases the mechanism that set $\tau^{\prime}\left(\theta_{1}\right)$ is sequentially implementable. In addition, it yields an expected social welfare that is at least as high as the expected social welfare in the original mechanism. This implies that there exists a second best mechanism with the property that there is $\theta^{1}$ such that $\tau\left(\theta^{1}\right)=V\left(\theta_{1}, \tilde{\theta}_{2}\left(\theta^{1}\right)\right)$. The rest of the proof appears in the body of the text.

\section{Proof of Theorem 7}

I now show the formal proof for the case where (1) holds; the case where (2) holds is proven by a similar argument. First, I denote by $[\underline{v}, \bar{v}]$ the segment of all $\theta^{1}$ such that there exists $\theta^{2}$ where $\left(\theta^{1}, \theta^{2}\right) \in \bar{V}^{S B}$. I define $\theta^{2}\left(\theta^{1}\right)$ to be the function that assigns to any $\theta^{1} \in[\underline{v}, \bar{v}]$ the threshold type it inflicts with respect to $\theta^{2}$, i.e., $\stackrel{\circ}{ }^{2}\left(\theta^{1}\right):=$ $\theta^{2}$ s.t. $\left(\theta^{1}, \theta^{2}\right) \in \bar{V}^{S B}$. Assume that (1) holds and consider some $\varepsilon$ such that $\dot{\theta}^{1}+\varepsilon<$ $\bar{u}$. Let

$$
V^{\prime}:=\max _{\theta^{1} \in\left[\dot{\theta}^{1}+\varepsilon, \bar{u}\right]} V\left(\theta^{1}, \tilde{\theta}^{2}\left(\theta^{1}\right)\right)
$$

and we have that $V^{\prime}<V\left(\dot{\theta}^{1}, \tilde{\theta}^{2}\left(\dot{\theta}^{1}\right)\right)$. I define $\hat{\theta}^{2}\left(\theta^{1}\right)$ as follows:

$$
\hat{\theta}^{2}\left(\theta^{1}\right)= \begin{cases}\theta^{2} \text { s.t. } V_{i}\left(\theta^{1}, \theta^{2}\right)=V^{\prime} & \text { if } \operatorname{such} \theta^{2} \text { exists } \\ 0 & \text { otherwise }\end{cases}
$$

Define the function $\tilde{C}\left(\theta^{1}\right)$ as follows:

$$
\tilde{C}\left(\theta^{1}\right)= \begin{cases}1 & \text { if } 0 \leq \theta^{1}<\underline{v} \\ \check{\theta}^{2}\left(\theta^{1}\right) & \text { if } \underline{v} \leq \theta^{1} \leq \dot{\theta}^{1}+\varepsilon \\ \hat{\theta}^{2}\left(\theta^{1}\right) & \text { if } \dot{\theta}^{1}+\varepsilon<\theta^{1} \leq \bar{u} \\ 0 & \text { if } \bar{u}<\theta^{1} \leq 1\end{cases}
$$

Consider a decision rule $\tilde{q}(\theta)$ that takes the following form:

$$
\tilde{q}(\theta)= \begin{cases}1 \text { if } & \theta^{2} \geq \tilde{C}\left(\theta^{1}\right) \\ 0 & \text { otherwise }\end{cases}
$$


The function $V\left(\theta^{1}, \tilde{C}\left(\theta^{1}\right)\right)$ is decreasing in the segment $\left[\underline{\theta}^{1, \tilde{C}}, \bar{\theta}^{1, \tilde{C}}\right]$ and therefore $\tilde{q}(\theta)$ is implementable by a sequential mechanism. To see that the social welfare under $\tilde{q}(\theta)$ is greater than under $q^{S B}(\theta)$, note that $q^{S B}(\theta)$ and $\tilde{q}(\theta)$ coincide except for a set of positive measure that lies above the boundary of the efficient decision rule in which $\tilde{q}(\theta)$ allocates the item to the buyer and $q^{S B}(\theta)$ allocates the item to the seller.

\section{References}

Athey, S., Segal, I.: An efficient dynamic mechanism. Econometrica 81(6), 2463-2485 (2013)

Baron, D.P., Besanko, D.: Regulation and information in a continuing relationship. Inf. Econ. Policy 1(3), 267-302 (1984)

Battaglini, M.: Long-term contracting with Markovian consumers. Am. Econ. Rev. 95(3), 637-658 (2005)

Bergemann, D., Välimäki, J.: The dynamic pivot mechanism. Econometrica 78(2), 771-789 (2010)

Bergemann, D., Wambach, A.: Sequential information disclosure in auctions. J. Econ. Theory 159, 10741095 (2015)

Chen, Y.C., He, W., Li, J., Sun, Y.: Equivalence of stochastic and deterministic mechanisms. Econometrica 87(4), 1367-1390 (2019)

Courty, P., Li, H.: Sequential screening. Rev. Econ. Stud. 67(4), 697-717 (2000)

Cremer, J., McLean, R.P.: Optimal selling strategies under uncertainty for a discriminating monopolist when demands are interdependent. Econometrica 53, 345-361 (1985)

Dai, C., Lewis, T.R., Lopomo, G.: Delegating management to experts. Rand J. Econ. 37(3), 503-520 (2006)

Dana, J.D., Jr., Spier, K.E.: Designing a private industry: government auctions with endogenous market structure. J. Public Econ. 53(1), 127-147 (1994)

Dasgupta, P., Maskin, E.: Efficient auctions. Q. J. Econ. 115(2), 341-388 (2000)

Deb, R., Said, M.: Dynamic screening with limited commitment. J. Econ. Theory 159, 891-928 (2015)

Esőo, P., Szentes, B.: Optimal information disclosure in auctions and the handicap auction. Rev. Econ. Stud. 74(3), 705-731 (2007a)

Eső, P., Szentes, B.: The price of advice. Rand J. Econ. 38(4), 863-880 (2007b)

He, W., Li, J.: Efficient dynamic mechanisms with interdependent valuations. Games Econom. Behav. 97, 166-173 (2016)

Hoffmann, F., Inderst, R.: Pre-sale information. J. Econ. Theory 146(6), 2333-2355 (2011)

Jarman, F., Meisner, V.: Deterministic mechanisms, the revelation principle, and ex-post constraints. Econ. Lett. 161, 96-98 (2017)

Jehiel, P., Moldovanu, B.: Efficient design with interdependent valuations. Econometrica 69(5), 1237-1259 (2001)

Jehiel, P., Moldovanu, B.: The design of an efficient private industry. J. Eur. Econ. Assoc. 2(2-3), 516-525 (2004)

Johnson, S., Miller, N.H., Zeckhauser, R.: Mechanism design with multidimensional, continuous types and interdependent valuations. J. Econ. Theory 136(1), 476-496 (2007)

Krähmer, D., Strausz, R.: Optimal procurement contracts with pre-project planning. Rev. Econ. Stud. 78(3), 1015-1041 (2011)

Krähmer, D., Strausz, R.: Ex post information rents in sequential screening. Games Econom. Behav. 90, 257-273 (2015)

Krähmer, D., Strausz, R.: Optimal sales contracts with withdrawal rights. Rev. Econ. Stud. 82(2), 762-790 (2015)

Krähmer, D., Strausz, R.: Sequential versus static screening: an equivalence result. Games Econom. Behav. 106, 317-328 (2017)

Laffont, J., Martimort, D.: The Theory of Incentives: The Principal-Agent Model. Princeton University Press, Princeton (2002)

Li, H., Shi, X.: Discriminatory information disclosure. Am. Econ. Rev. 107(11), 3363-85 (2017)

Liu, H.: Efficient dynamic mechanisms in environments with interdependent valuations: the role of contingent transfers. Theor. Econ. 13, 795-829 (2017) 
Maskin, E.: Auctions and privatization. In: Siebert, H. (ed.) Privatization, pp. 115-136. Mohr, Tubingen (1992)

Mezzetti, C.: Mechanism design with interdependent valuations: efficiency. Econometrica 72(5), 16171626 (2004)

Myerson, R.B.: Optimal auction design. Math. Oper. Res. 6(1), 58-73 (1981)

Myerson, R.B.: Multistage games with communication. Econometrica 54(2), 323-358 (1986)

Nocke, V., Peitz, M., Rosar, F.: Advance-purchase discounts as a price discrimination device. J. Econ. Theory 146(1), 141-162 (2011)

Pavan, A., Segal, I., Toikka, J.: Dynamic mechanism design: a Myersonian approach. Econometrica 82(2), 601-653 (2014)

Perry, M., Reny, P.J.: An efficient auction. Econometrica 70(3), 1199-1212 (2002)

Rochet, J.C.: A necessary and sufficient condition for rationalizability in a quasi-linear context. J. Math. Econ. 16(2), 191-200 (1987)

Strausz, R.: Deterministic mechanisms and the revelation principle. Econ. Lett. 79(3), 333-337 (2003)

Vohra, R.V.: Mechanism Design: A Linear Programming Approach, vol. 47. Cambridge University Press, Cambridge (2011)

Publisher's Note Springer Nature remains neutral with regard to jurisdictional claims in published maps and institutional affiliations. 